\title{
Inter-enterprise Collaborative Management for Patent Resources Based on Multi-agent
}

\author{
Liping Zhi ${ }^{1} \&$ Yanfei Ma ${ }^{1}$ \\ ${ }^{1}$ School of Computer Science \& Information Engineering, Anyang Normal University, Anyang, China \\ Correspondence: Liping Zhi. Tel: 86-135-0372-8754. E-mail: 13503728754@163.com
}

Received: September 14, 2017

Accepted: November 17, 2017

Online Published: December 27, 2017

doi:10.5539/ass.v14n1p54

URL: https://doi.org/10.5539/ass.v14n1p54

The research is financed by the Henan Philosophy and Social Science Project (No. 2015CZH004) \& the Training Scheme for Young Key Teachers in Universities of Henan (No. 2016GGJS-123) \& the Key Project of Science and Technology Research of Education Department of Henan (No. 16A520040) \& the Humanities and Social Science Project of Education Department of Henan (No. 2017-ZDJH-002) \& the Soft Science of Intellectual Property Rights of Henan (No. 20170106026) \& the Research and Development Fund of Anyang Normal University (No. $A Y N U-K P-B 07)$.

\begin{abstract}
Based on relevant literature and theoretical consideration on management for patent resources, a theory of inter-enterprise collaborative management for patent resources (ICMPR) based on multi-agent was proposed. We put forward 4 main function modules, including collaborative recommendation, collaborative analysis, collaborative application and system server management, to support ICMPR. The ICMPR can be good to solve those tough and important problems, such as patent cross licensing among enterprises, early warning analysis of patents, collaborative technology innovation and other issues. The ICMPR can provide enterprises with practical methodology, and improve the overall competitiveness of world manufacturing industry.
\end{abstract}

Keywords: Collaborative management, Patent resources, ICMPR, Recommendation technology

\section{Introduction}

In knowledge-based economy age, the management of intellectual properties has become more and more important for an enterprise. For most enterprises, patent is the core part of intellectual properties, and it is very important intangible assets. In the enterprise management, it can often bring more value than tangible assets. Patents imply some methods of solving problems, which can quickly and systematically reflect the development of technologies or related disciplines. The World Intellectual Property Organization revealed that $90-95 \%$ of world's inventions were found in patented documents. If the related patent information can be effectively used, modern enterprises will raise the starting point of scientific research and save funds and time in the development course. Besides, they also will get their own intellectual property rights, reliable technical support and high value-added products to improve the ability of market competitiveness of enterprises (Soo et al., 2006).

Modern products are often the integration of many technologies, which could never be finished by one enterprise independently. Therefore, inter-enterprise collaborative management for patent resources (ICMPR) is becoming the urgent demand for enterprises. Inter-enterprise resources collaborative management, as a brand-new kind of management mode, has become one of the hotspots for research (Xin-Jian, 2010). In order to promote comprehensive cooperation and innovation in the collaborative environment, our research objective is to propose an integrated system that contains collaborative recommendation, collaborative Analysis, collaborative application and system server management. This paper study in the patent domain, and the research question is inter-enterprise collaborative management for patent resources (ICMPR).

\section{Related work}

The European Patent Office disclosed "more than $80 \%$ of man's technical knowledge is described in patent literature". Unfortunately, most studies in the patent document analysis are on document search and classification (Fall et al., 2004), very few discussed how to use the patent documents to further support advanced management including the recommendation, analysis and application(Soo et al., 2006). Therefore, how to 
establish a collaborative platform to automatically recommend the useful patent knowledge from patent documents in order to further support the collaborative management among enterprises becomes an essential topic.

Activities in the collaborative management process are usually distributed across managers, experts, teams, departments from different enterprises. Multi-agent systems (MAS) (Wang et al., 2000) offer a new dimension for cooperation and coordination in an enterprise. A MAS consists of a collection of autonomous agents who can define their own goals and actions and can interact and collaborate among each other through communication. In a MAS environment, multi-agent work collectively to solve specific problems. It provides an effective platform for coordination and cooperation among multiple functional units in a company. Multi-agent systems have already been proposed for supporting distributed decision-making in as many fields as engineering (Tan \& Harker, 1999), manufacturing (Lee \& Lee, 1999), business (Jung \& Jo, 2000). In this paper, how to use a collaborative multi-agent platform to make the management process effectively is one of the major goals of the research (Timothy et al., 2002; Ali \& Coskun, 2007; Agnieszka et al., 2010).

\section{Methodology}

To meet user's requirements from four different levels, the research on the ICMPR can be divided into four stages of implementation, which are respectively personal, business unit, enterprise group, cooperation among enterprises. We focus on the cooperation among enterprises, as shown in figure 1.

Several steps are taken for this study. The brief description of the steps in the methodology is as follows:

The first step is to have a collection of patent resources, including the knowledge mining and analysis of patents and patent evaluation, in order to realize collaborative recommendation function for patents;

The second step is to complete the early warning of patents, collaborative evaluation for patent resources.

The third step is to complete the construction of patent standard, collaborative protection of patents, collaborative technology innovation, collaborative portfolio management of patents, patent cross licensing among enterprises.

Ended up with the Haier group to study, looking forward to application prospect of theories proposed by the paper.

\section{An overview of the proposed collaborative multi-agent platform}

\subsection{Function model of ICMPR based on multi-agent}

Collaborative management for patent resources using agent technology will provide all kinds of intelligent retrieval, mining, analysis and service function. The environment of ICMPR has distribution, openness, heterogeneity, mobility and collaborative etc. Due to the complex, multi-levels and the interactive relationships existed in human society, the calculation based on agent, especially MAS (Multi-Agent System) and mobile agent, has many outstanding advantages in the analyzing and establishing people-oriented inter-enterprise patent resources management system. In order to reduce the difficulty in implementation of ICMPR, the cooperative mode should be loose coupling model rather than tightly coupled, and the centralized collaborative mode will be changed into the distributed collaborative mode. Publication and application of ICMPR is in the form of web-sites, on which safety problems also should be paid attention to.

Based on the above analysis, main functions of inter-enterprise collaborative management systemfor patent resources (ICMSPR) based on Multi-agent are shown in fig.2 (Xin-Jian, 2010; Guo-Hai, 2007). We can see from fig.2, collaborative recommendation for patent resources is the basis of the whole system, which also offers important premise for collaborative analysis, the application of patent resources. Therefore, towards the ICMPR based on multi-agent proposed by this paper, the study of patent resources collaborative recommendation technology is very important, and will be described detailed in section 4.2. In addition, the study of patent resources collaborative analysis will be described detailed in section 4.3, the study of patent resources collaborative application will be described detailed in section 4.4 , the study of system server management will be described detailed in section 4.5 .

\subsection{Collaborative recommendation}

Along with the explosion of information, it is more and more difficult to acquire knowledge from the Internet. For example, we can retrieve "TV" patents from the website of China's intellectual property rights (http://www.cnipr.com/) for almost 1050 pages (10493 correlative patents in total), among which there are 2728 invention patents, 4178 utility patents, 3888 appearance design patents. Then, how to retrieve useful relevant patents for users from vast intellectual property database and recommend users automatically so as to realize 
personalized service? However, there isn't any recommendation intelligent technique that has been applied to patent information research. Studying of intelligence recommendation technology based on patents, has an important foundational role for the ICMPR proposed by this paper, also can be applied to patent retrieval system and web, for it could greatly improve the retrieval efficiency of patents. Our research will have a positive influence on the intellectual property in the world (Lee et al., 2007; Liebowitz et al., 2007).

\subsection{Collaborative analysis}

To make a further analysis on substantive, finer-grained patent information and supply a more valuable analysis report, these could never be finished by one enterprise independently. As showed in fig.2, collaborative analysis contains early warning analysis of patents, patent combination management, patent cross licensing among enterprises, data mining for patent resources. The knowledge mining and analysis of patents include: the statistical methods of patent information, technology analytical method based on patents, the patent rights analysis, etc.

Patent information statistics methods mainly use commercial software for data mining, while, technical analysis and right analysis for patents use the patent knowledge mining technology and agent technology to support decisions for enterprises ( $\mathrm{Wu}, 2009)$.

Early warning analysis of patents include: introducing to the latest patent information and statistics, establishing qualitative evaluation guidelines for early warning of patents, drawing up the patent map, etc. Patent portfolio management is a strategic collection of some patents under a common control which are distinct but related. Patent portfolio management, including: establishing evaluation guidelines for patent portfolio, establishing the relations between patents and products, calculating the effectiveness of patents and Relative technical share, analyzing of patent portfolio, etc. Patent cross licensing among enterprises including: management for patent pools, evaluation on patents, management for patent cross licensing among enterprises.

\subsection{Collaborative application}

There are a lot of applications of patent resources, which need even more to be cooperatively executing among enterprises, as showed in fig.2, including patent collaborative protection, patent training, collaborative technology innovation, collaborative construction of standard, etc. Collaborative protection for patent include information management of products' patent protection, data management of patent infringement, acquisition and analysis on patent information of export countries, information management of patent system and regulations of export countries, aiming to support enterprises in the policy analysis and strategy analysis; Patent training aims to ascend patent awareness and sensitivity, cultivating patent talents, stimulate the ability to innovate and improve patent retrieval and analysis capability (Lin \& Tseng, 2006).

Collaborative technology innovation based on patent contain acquisition and analysis of patent information of related products and technology, acquisition and analysis of patent information in the target market, collaborative technical innovation management based on patents, establishing information interaction platform to support collaborative technological innovation.

\subsection{System Service Management}

System service management is necessary to co-ordinate all of the services, and it is a system to ensure the efficient operation of the system, including:

(1) User management: Management for users' data in the system.

(2) Authority management: It gives different permissions to different users, and provides different services according to the different permissions.

(3) Log management: Management the use of this system for users.

(4) Repository management: Regular management of all kinds of patent resources in the system.

\section{Conclusion}

This paper studies the technologies of inter-enterprise collaborative management for patent resources (ICMPR), and proposes its function model, then gives a detailed introduction of its four functions, especially collaborative recommendation. Aiming at realizing the function of collaborative recommendation, the paper gives a hybrid collaborative filtering algorithm, to make up for the blank of the patent recommendation. Last, we choose the Haier group to forecast the future application of ICMPR, which can raise the management level of patents to support enterprises to develop collaborative analysis for patents and improve the capacity for independent innovation of enterprises. 
Inter-enterprise collaborative management for patent resources (ICMPR) proposed by this paper can provide enterprises with practical methodology, and improve the overall competitiveness of world manufacturing industry.

\section{References}

Agnieszka, S. L., Supakij, C., Arkhom, S., \& Kongkiti, P. (2010). Applying social network analysis on customer complaint handling. Industrial Management \& Data Systems, 110(9), 1402-1419. https://doi.org/10.1108/02635571011087455

Fall, C. J., Torcsvari, A., Benzineb, K., \& Karetka, G. (2004). Automated categorization of German-language patent documents. Expert Systems with Applications, 26, 269-277. https://doi.org/10.1016/S0957-4174(03)00141-6

Guo-Hai, C. (2007).Research on Some Key Technologies of Enterprise Patent Management \& Analysis System. Master Thesis, Zhejiang university, pp. 15-16.

Lee, S., Lee, Z. \& Lee, J. (2007). Knowledge transfer in work practice: adoption and use of integrated information Systems. Industrial Management \& Data Systems, 107(4), 501-518. https://doi.org/10.1108/02635570710740661

Liebowitz, J., Ayyavoo, N., Nguyen, H., Carran, D. and Simien, J. (2007). Cross-generational knowledge flows in edge organizations. Industrial Management \& Data Systems, 107(8), 1123-1153. https://doi.org/10.1108/02635570710822787

Lin, C. \& Tseng, H. (2006). Identifying the pivotal role of participation strategies and information technology application for supply chain excellence. Industrial Management \&Data Systems, 106(5), 739-56. https://doi.org/10.1108/02635570610666476

Soo, V.-W., Lin, S.-Y., Yang, S.-Y., Lin, S.-N., \& Cheng, S.-L.(2006). A cooperative multi-agent platform for invention based on patent document analysis and ontology. Expert Systems with Applications, 31(4), 766-775. https://doi.org/10.1016/j.eswa.2006.01.014

Tan, J. C., \& Harker, P. T. (1999). Designing workflow coordination: centralized versus market-based mechanisms. Information Systems Research, 10(4), 328-342. https://doi.org/10.1287/isre.10.4.328

Timothy, K. S., Chuanfeng, C., Huihuang, H. \& Fuhua L. (2002). An integrated framework for recommendation systems in e-commerce. Industrial Management \& Data Systems, 102(8), 417-431. https://doi.org/10.1108/02635570210445853

Wang, A., Conradi, R., \& Liu, C. (2000). A multi-agent architecture for cooperative software engineering. In: Twelfth international conference of software engineering and knowledge engineering (SEKE'2000).

Wu, L. (2009). Supplier selection under uncertainty: a switching options perspective. Industrial Management \& Data Systems, 109(2), 191-205. https://doi.org/10.1108/02635570910930091

Xin-Jian, G. The National High Technology Development 863 Program of China: Research on Inter-enterprise Collaborative management for patent resources Model and its Software technology [EB/OL]. [2010-12-1]. http://www.ie.zju.edu.cn/m/ie/download/2008zanban-zhuanli.pdf

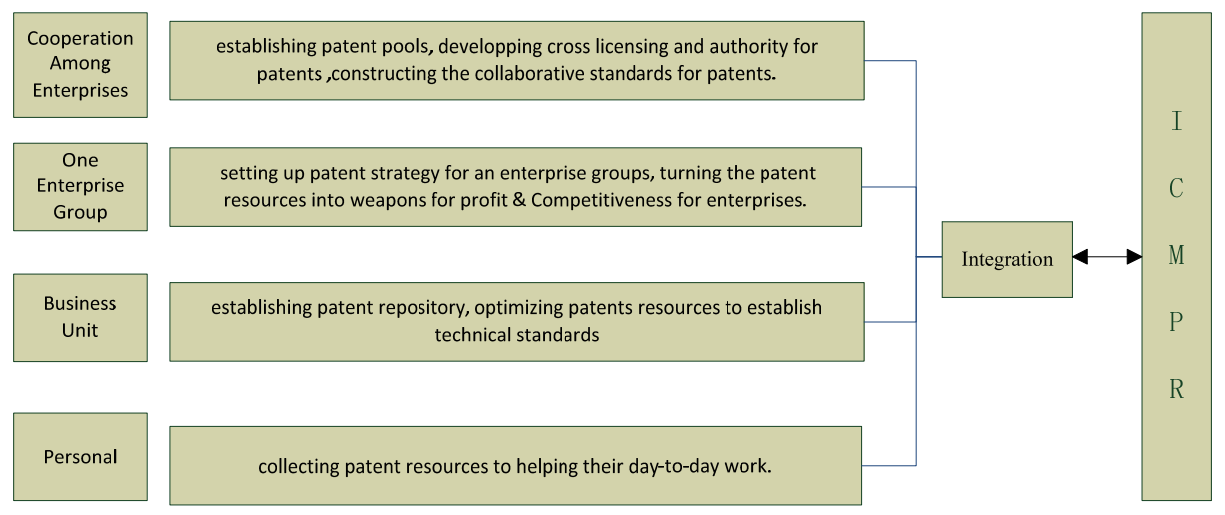

Figure 1. ICMPR for Different Levels 


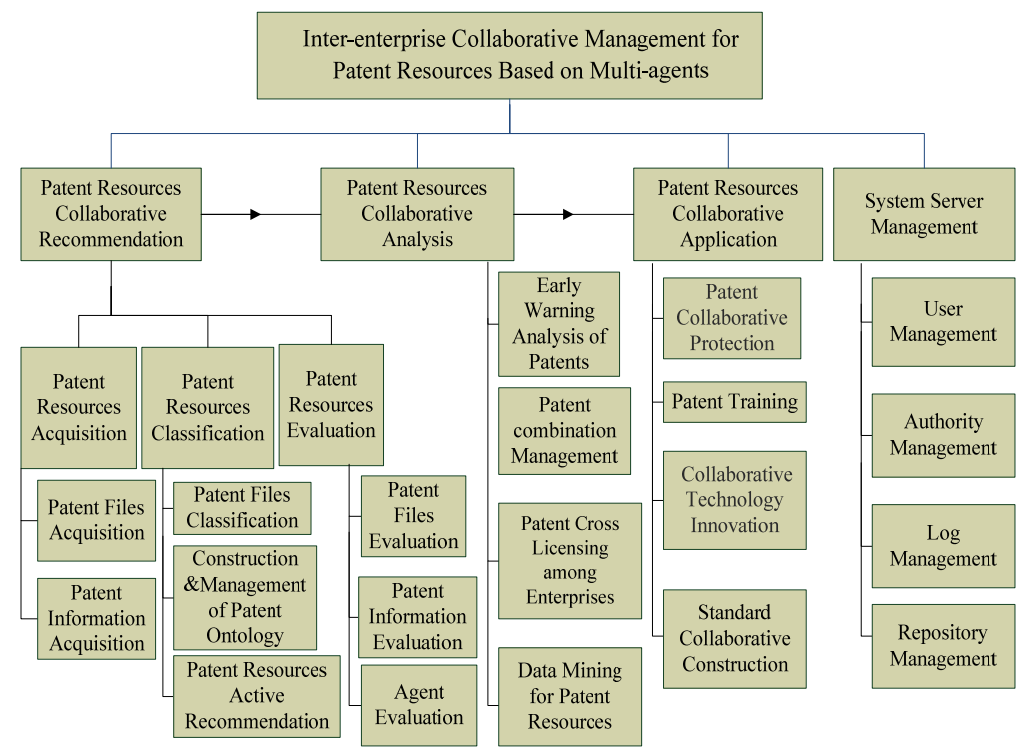

Figure 2. Function model of inter-enterprise collaborative management system for patent resources

\section{Copyrights}

Copyright for this article is retained by the author(s), with first publication rights granted to the journal.

This is an open-access article distributed under the terms and conditions of the Creative Commons Attribution license (http://creativecommons.org/licenses/by/4.0/). 